\title{
Constituintes das sementes de Copaifera officinalis $\mathrm{L}$.
}

\author{
Valdir F. VEIGA JUNIOR ${ }^{1,4}$, Martinho A. ANDRADE JUNIOR ${ }^{2}$, Isolde D. K. FERRAZ 3 , Herick B. \\ CHRISTO $^{4}$, Angelo C. PINTO ${ }^{4}$
}

\section{RESUMO}

O gênero Copaifera L. é um dos mais importantes economicamente na Região Amazônica devido, principalmente, à produção dos óleos de copaíba, oléo-resinas com diversas propriedades farmacológicas confirmadas. Apesar disso, os estudos fitoquímicos com as sementes das árvores do gênero Copaifera L. são raros. Copaifera officinalis foi a primeira espécie do gênero Copaifera a ser descrita. Este trabalho descreve a composição dos extratos obtidos em hexano e em acetato de etila das sementes de $C$. officinalis. No extrato obtido em hexano, a análise por cromatografia em fase gasosa utilizando padrōes e através de espectrometria de massas permitiu a identificação de: esqualeno, tetradecano, hexadecano, campesterol, estigmasterol e $\beta$-sitosterol; os ácidos graxos hexadecanóico, 9-octadecenóico e octadecanóico (majoritários); e decanóico, eicosanóico, docosanóico e tetracosanóico (minoritários). Cumarina foi isolada do extrato em acetato de etila e identificada por técnicas de RMN.

PALAVRAS-CHAVE

Copaifera officinalis L.; cumarina; ácidos graxos.

\section{Constituents from Copaifera officinalis $L$. seeds}

\section{ABSTRACT}

Copaifera $L$. is one of the most economically important plant genera in the Amazon Region, since it exudes a resin-oil named copaiba oil possessing several confirmed pharmacological properties. In spite of that, phytochemical studies of the seeds from this genus are rare. Copaifera officinalis $L$. was the first species in the genus Copaifera to be described. This paper describes the chemical composition of the hexane and ethyl acetate extracts of the seeds from this species. In the hexane extract, gas chromatography and mass spectrometry analyses enabled us to identify squalene, tetradecane, hexadecane, campesterol, stigmasterol and $\beta$-sitosterol; hexadecanoic, 9-octadecenoic and octadecanoic acids (major substances); as well as decanoic, eicosanoic, docosanoic and tetracosanoic (minor substances) acids. Coumarin was detected in the ethyl acetate extract, isolated and identified by NMR.

\section{KEY-WORDS}

Copaifera officinalis L.; coumarin; fatty acids.

\footnotetext{
${ }^{1}$ Departamento de Química, Instituto de Ciências Exatas, Universidade Federal do Amazonas, Av. Gal. Rodrigo Octávio Jordão Ramos 3000, Japiim, 69079-000 Manaus, Brasil. ${ }^{2}$ Museu Integrado de Roraima/Setor de Botânica, Boa Vista/RR - Brasil.

${ }^{3}$ Instituto Nacional de Pesquisas da Amazônia/Coordenação de Pesquisas em Silvicultura Tropical (INPA/CPST), Manaus/AM - Brasil.

${ }^{4}$ Instituto de Química, Universidade Federal do Rio de Janeiro, CT, Bloco A, Cidade Universitária, Illha do Fundão, 21945-970 Rio de Janeiro, Brasil.
} 


\section{INTRODUÇÃO}

O gênero Copaifera é constituído de espécies de elevado valor econômico e ecológico, não somente na Amazônia, mas em todo o continente Sul-Americano. Adaptadas aos diversos climas brasileiros, suas árvores exudam um óleo-resina chamado de óleo de copaíba, cujas propriedades biológicas são amplamente descritas na literatura (Veiga Junior \& Pinto, 2002; Veiga Junior et al., 2001; Lima et al., 2003).

A espécie Copaifera officinalis foi a primeira a ser descrita, por Lineu, em 1762. Esta foi, provavelmente, a principal espécie de copaíba cujos óleos foram comercializados através do Caribe nos primeiros tempos de colonização da América, nos séculos XVI e XVII, por ser a de maior freqüência na Amazônia setentrional, no extremo norte do Brasil, em Roraima, da Venezuela às Antilhas (Andrade Junior, 1998; Andrade Junior \& Ferraz, 2000), sendo chamada pelos indígenas de Copaíba Maracaibo. Atualmente, os óleos de copaíba obtidos desta espécie ainda são comercializados na região, especialmente na cidade de Boa Vista, Roraima (Pinto \& Maduro, 2003).

Apesar deste histórico, os estudos envolvendo esta espécie são raros e não descrevem o local de coleta, o que levanta dúvidas quanto à sua identificação botânica. Nas três principais regiôes fornecedoras e exportadoras de óleos de copaíba: a região de Belém do Pará e Maranhão (Amazônia Oriental), onde predomina a C. reticulata; a região do Acre (Amazônia Ocidental), onde predomina a $C$. paupera; e mesmo na região próxima a Manaus (Amazônia Central), onde a espécie endêmica é a Copaifera multijuga (Veiga Junior \& Pinto, 2002); o número reduzido de espécimes de $C$. officinalis talvez explique o fato desta ser uma das espécies menos estudadas neste gênero, apesar de sua importância econômica.

A disseminação de $C$. officinalis depende diretamente dos agentes dispersores das sementes, em geral, tucanos, que são atraídos provavelmente pelo seu arilo amarelado, mas também pelo odor de cumarina exalado das sementes. Diversos estudos já foram realizados sobre a composição e conservação de sementes das espécies C. multijuga (Façanha \& Varela, 1986; Garcia \& Lima, 2000) e C. langsdorfii (Oliveira \& Queiroz, 1995). Os estudos fitoquímicos de sementes, entretanto, são raros. Constam da literatura apenas duas citações: a primeira, de 1894 (Ficalho, 1894), de C. salikonda, uma espécie de copaíba africana, e outra, mais recente, de 1959 (Mors \& Monteiro, 1959), de $C$. langsdorfii. Nos dois estudos foi descrita a presença da cumarina e, no mais recente, também da umbeliferona.

Depois de ser utilizada por vários anos na indústria alimentícia, a cumarina foi praticamente banida do mercado devido à sua toxicidade. Apesar disso, extratos hidroalcoólicos de Torresea cearensis, Justicia pectoralis, Eclipta alba, Pterodon polygaliflorus e Hybanthus ipecacuanha, ricos em cumarina, são largamente empregadas pela medicina popular do nordeste do país (Leal et al., 2000).
O objetivo deste estudo é descrever a composição química dos extratos em hexano e em acetato de etila das sementes de $C$. officinalis $\mathrm{L}$.

\section{MATERIAL E MÉTODOS}

O espécime de C. officinalis L. estudado foi localizado na região conhecida como Jardim das Copaíbas, na Mata de Galeria da margem direita do rio Branco, cerca de $12 \mathrm{~km}$ ao Sul de Boa Vista/RR, nas proximidades do Distrito Industrial, nas coordenadas geográficas: 2० 46' N e 60 41' O.

$\mathrm{O}$ espécime possui altura estimada de $25 \mathrm{~m}$, com circunferência à altura do peito - CAP de $1,30 \mathrm{~m}$ acima da superfície do solo; $3,0 \mathrm{~m}$; e diâmetro à altura do peito - DAP de $0,95 \mathrm{~m}$. A coleta das sementes e a identificação da espécie foram realizadas pelo botânico Martinho de Andrade Júnior, pesquisador do Museu Integrado de Roraima (MIRR). Duas exsicatas foram preparadas e depositadas nos herbários do MIRR (5.517) e do Instituto Nacional de Pesquisas da Amazônia (INPA 191.211).

As sementes analisadas foram coletadas em setembro de 1998, pesadas $(146 \mathrm{~g})$ e armazenadas em geladeira por cerca de 6 meses. Para a obtenção dos extratos, as sementes foram quebradas, moídas e submetidas à extração com hexano $(3,6 \mathrm{~g}$, rendimento de $2,4 \%)$, acetato de etila $(4,9 \mathrm{~g}$, rendimento de $3,4 \%)$ e metanol $(10,2 \mathrm{~g}$, rendimento de $7,0 \%)$. A taxa de germinação dessas sementes foi superior a $90 \%$.

O extrato obtido em hexano foi esterificado com diazometano para a análise direta por cromatografia em fase gasosa (CG) e com acoplamento à espectrometria de massas (CG-EM). A identificação das substâncias presentes no extrato obtido em hexano foi realizada através de seus espectros de massas, índices de retenção e através de co-eluição com padrōes.

As análises cromatográficas foram realizadas em cromatógrafo a gás, modelo HP-5790, com detector de ionização de chama (FID) com hidrogênio como gás de arraste, com vazão de 2,0 $\mathrm{ml} . \mathrm{min}^{-1}$, e coluna de vidro de fase estacionária SE- 54 (L $=25$ $\mathrm{m} ; \mathrm{DI}=0,25 \mathrm{~mm} ; \mathrm{EF}=0,25 \mathrm{~mm}$ ). Os espectros de massas foram obtidos por impacto de elétrons, $70 \mathrm{eV}$, na faixa de $40 \mathrm{a}$ $600 \mathrm{u}$, com analisador quadrupolo e modo de aquisição por varredura linear (scan), em equipamento HP5897A, conectado a um cromatógrafo a gás HP5880. Foi utilizado hélio como gás de arraste $\left(1,5 \mathrm{ml} \cdot \mathrm{min}^{-1}\right)$ e coluna idêntica àquela utilizada nos experimentos de cromatografia em fase gasosa.

As análises de ressonância magnética nuclear de ${ }^{1} \mathrm{H}(300$ $\mathrm{MHz})$ e de ${ }^{13} \mathrm{C}(75 \mathrm{MHz})$ foram feitas em aparelho Brüker modelo AC-300, em clorofórmio deuterado, utilizando tetrametilsilano (TMS) como padrão.

\section{RESULTADOS E DISCUSSÃO}

Devido à grande quantidade de ácidos graxos no extrato obtido em hexano, foi realizado o fracionamento deste extrato 
em coluna de sílica impregnada com KOH (Pinto et al, 2000), para a separação dos ácidos carboxílicos dos constituintes minoritários. As análises cromatográficas (CG e CG-EM) utilizando padrōes permitiram a identificação de diversos constituintes dos extratos. $\mathrm{Na}$ fração ácida do extrato obtido em hexano a análise por CG e CG-EM permitiu, após esterificação com diazometano, a identificação de diversos ácidos graxos na forma de seus ésteres metílicos: hexadecanóico (palmítico), 9octadecenóico (oléico) e octadecanóico (esteárico), entre os majoritários; e decanóico, eicosanóico (aráquico), docosanóico (behênico) e tetracosanóico (lignocérico), entre os minoritários. $\mathrm{Na}$ fração não-ácida foram detectados o 2,4-decadienal e o etoxisuccinato de dimetila, e os hidrocarbonetos tetradecano, hexadecano e esqualeno $(2,6,10,15,19,23$-hexametil2,6,10,14,18,22-tetracosahexaeno), identificados utilizando o conjunto de técnicas cromatográficas e de espectrometria já citados. Uma mistura de esteróis comumente observados em óleos de sementes (Abidi, 2001), campesterol, estigmasterol e $\beta$ sitosterol também foi identificada na fração não-ácida.

A análise por CG-EM do extrato obtido em acetato de etila evidenciou a presença de diversos derivados de ácidos graxos e de grandes quantidades de cumarina. Procedeu-se, então, fracionamento através de cromatografia em coluna aberta de gel de sílica (utilizando gradiente de hexano: acetato de etila como eluente) e recristalização da fração rica em cumarina, que foi identificada através de seus dados de espectrometria de massas e de ressonância magnética nuclear de ${ }^{1} \mathrm{He} \mathrm{e}^{13} \mathrm{C}$, comparados aos da literatura (Harkar et al., 1984; Oertli et al., 1994).

Para a análise dos demais constituintes presentes no extrato obtido em acetato de etila procedeu-se a separação da cumarina, realizada utilizando-se sua propriedade de alta pressão de vapor à temperatura ambiente. $\mathrm{O}$ extrato foi inserido em baláo de vidro e submetido a aquecimento leve $\left(40^{\circ} \mathrm{C}\right)$ em evaporador rotatório à pressão reduzida, o que provocou a completa sublimação da cumarina e sua separação do restante do extrato após duas horas.

A análise por CG e CG-EM do extrato obtido em acetato de etila livre de cumarina permitiu a observação de ésteres metílicos e etílicos de ácidos graxos. Os ésteres metílicos dos ácidos palmítico, linoléico, oléico, esteárico, eicosênico e behênico observados neste extrato são relatados pela primeira vez no gênero Copaifera $\mathrm{L}$.

Ésteres etílicos são menos comuns em extratos vegetais mas sua presença neste extrato não pode ser determinada de forma inequívoca uma vez que estas substâncias podem ter sido formadas como artefatos do processo de extração, da reação de subprodutos do solvente com os ácidos graxos originais da amostra.

\section{CONCLUSÕES}

Apesar de ter sido a primeira espécie do gênero Copaifera $\mathrm{L}$. descrita, poucos foram os estudos sobre $C$. officinalis L. A utilização de técnicas cromatográficas de isolamento fitoquímico aliadas a métodos espectrométricos e espectroscópicos de análise permitiram a detecção e identificação de diversas substâncias nos extratos obtidos em hexano e acetato de etila das sementes de $C$. officinalis L., estudados pela primeira vez. Foram identificados, majoritariamente, ácidos graxos, mas também a cumarina, esteróis e hidrocarbonetos, como o esqualeno, o tetradecano e o hexadecano. As análises por cromatografia em fase gasosa permitiram ainda a detecção de ésteres metílicos de ácidos graxos, incomuns em sementes.

\section{BIBLIOGRAFIA CITADA}

Abidi, S.L. 2001. Chromatographic analysis of plant sterols in foods and vegetable oils. J. Chromatogr. A, 935: 173-201.

Andrade Júnior, M.A. 1998. Sementes de copaiba (Copaifera officinalis L. - Caesalpiniaceae): uma abordagem autoecológica, fisiológica e tecnológica. Dissertação de Mestrado. Instituto Nacional de Pesquisas da Amazônia, Universidade Federal do Amazonas, Manaus, AM. 114pp.

Andrade Júnior, M.A., Ferraz, I.D.K. 2000. Eventos Fenológicos de Copaíba (Copaifera officinalis L. - Caesalpiniaceae) em Mata de Galeria do Rio Branco, Boa Vista/Roraima, Brasil: Uma primeira aproximação. Acta Amazonica, 30: 523-533.

Façanha, J.G.V., Varela, V.P. 1986. Resultados preliminares de estudos sobre a conservação e composição bioquímica de sementes de copaíba (Copaifera multijuga Hayne) - Leguminosae. Acta Amazonica, 16/17: 377-382.

Ficalho, Apoth. Ztg. 1904, 86, em C. Wehmer "Die Pflanzenstoffe", G. Fisher, Jena, 1929, vol I, p. 499.

Garcia, L.C., Lima, D. 2000. Comportamento de sementes de Copaifera multijuga durante armazenamento.Acta Amazonica, 30: 369-375.

Harkar, S.; Razdan, T.K.; Waight, E.S. 1984. Steroids, chromone and coumarins from Angelica officinalis. Phytochemistry, 23: 419426.

Leal, L.K.A.M.; Ferreira, A.A.G.; Bezerra, G.A.; Matos, F.J.A.; Viana, G.S.B. 2000. Antinociceptive, anti-inflammatory and bronchodilator activities of Brazilian medicinal plants containing coumarin: a comparative study. J. Ethopharmacol., 70: 151-159.

Lima, S.R.M., Veiga Junior, V.F., Christo, H.B., Pinto, A.C., Fernandes, P.D. 2003. In vivo and in vitro studies on the anticancer activity of Copaifera multijuga Hayne and its fractions. Phytother. Res., 17: 1048-1053.

Mors, W.B.; Monteiro, H.J. 1959. Duas cumarinas nas sementes da Copaifera langsdorfii. An. Assoc. Bras. Quim., 18: 181-182.

Oertli, E.H.; Green, G.S.; Griffith, D.G.; Fowlks, W.L. 1984. Linear furocoumarins and other constituents from Thamnosma texana. Phytochemistry, 23: 439-441.

Oliveira, L.M.Q., Queiroz, S.R.O.D. 1995. Germinação das sementes de Copaifera langsdorfii Desf. de frutos em diferentes fases de maturação. Anais da Reunião Regional da SBPC, Cuiabá, 24 a 28 de abril de 1995 .

Pinto, A.A.C.; Maduro, C.B. 2003. Produtos e subprodutos da medicina popular comercializados na cidade de Boa Vista, Roraima. Acta Amazonica., 33: 281-290. 
Pinto, A.C., Braga, W.F., Veiga Junior, V.F., Patitucci, M.L., Garrido, F.M.S., Bergter, L., Antunes, O.A.C. 2000. Separation of acid diterpenes of Copaifera cearensis Huber ex Ducke by flash chromatography using potassium hydroxide impregnated silica gel. J. Braz. Chem. Soc., 11: 355-360.

Veiga Junior, V.F., Pinto A.C., Calixto, J.B., Zunino, L., Patitucci, M.L. 2001. Phytochemical and anti-oedematogenic studies of commercial copaíba oils available in Brazil. Phytother. Res., 15: 476-480.
Veiga Junior, V.F., Pinto, A.C. 2002. O gênero Copaifera L. Quim. Nova, 25: 273-286.

Recebido em 06/10/2006

Aceito em 24/01/2007 